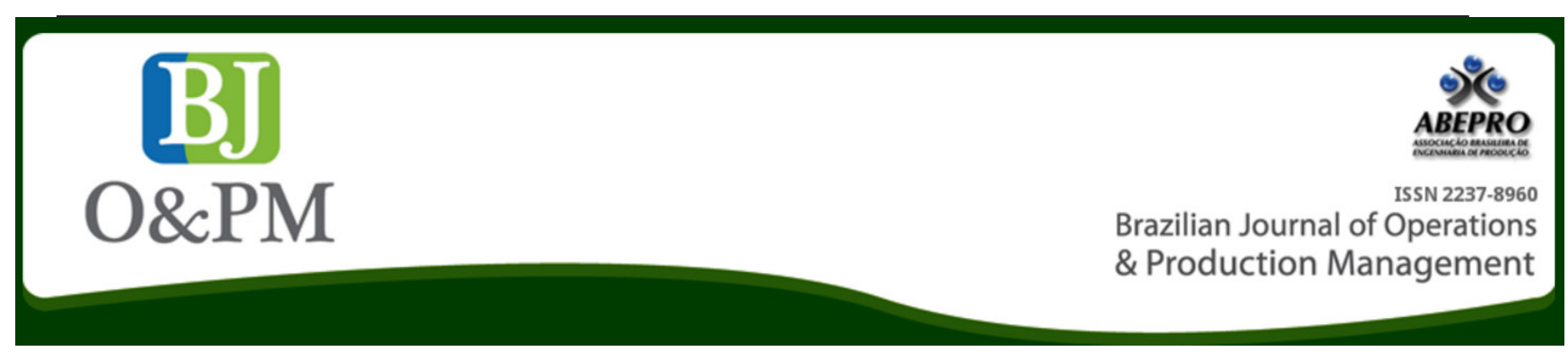

\title{
THE IMPORTANCE OF COST MANAGEMENT IN A MANUFACTURING COMPANY OF HYDROELECTRIC PLANTS - A CASE STUDY
}

\author{
Mario Fernando Mello; Amanda Barbosa Santos ${ }^{a}$ \\ a Lutheran University of Brazil (ULBRA) - Canoas, RS, Brazil
}

\begin{abstract}
Changes in the global market happen at all times and the update of the companies must be constant and rapid, thus it is necessary that managers are aware of the current status of the organization and its projects, mainly in cost sector. This paper aims to demonstrate the im-portance of cost managements and proposes a design methodology, through an applicative pro-gram for an appropriate management of costs in the studied company. The research occurred in the hydro sector on an assembly company of hydroelectric plants in the state of Rio Grande do Sul, Brazil. The survey results showed the importance of cost control in each project and this topic is part of the company financial policy. The results of this study show that a methodological structuring of cost control is vital for managers to have reports at hand in a proper sequence information, that is relevant to make decisions.
\end{abstract}

Keywords: Costs; Cost Management; Project Management

\section{INTRODUCTION}

Currently, the market is increasingly competitive and companies that seek to be competitive need to improve and control their processes increasingly. According to Bornia (2010), to achieve this improvement in the productive system, the modern company has some peculiarities that distinguish it from the traditional ones, among them stand out the continuous process of improvement, combating waste and the implementation of the philosophy of total quality.

As a result, companies must learn what they are doing, who they are working for and must also control how much they are doing. The quality and the control interfere directly in the success of the project.

The lack of a cost management system can affect profits and business processes. Thus, this study aims to demonstrate the importance of cost management as well as develop a methodology for the organization to better manage their projects and their cost structures. The company researched here is a company engaged in the provision of electromechanical assembly services in hydroelectric plants.

The management and costs are always factors that stand out in organizations because of the important role that they transmit and result. Increasingly, the highlight of these areas is growing and becoming important for the proper performance

ABEPRO

DOI: 10.14488/BJOPM.2016.v13.n1.a11 of the company. Practices that consider the alignment of these two terms need to be applied in organizations.

The study aims to show information relating to costs, cost management and project management, and may provide a basis for companies to develop strategies to have a more competitive profile market.The study also aims to provide information on the cost structure through the development of a specific applicative in the project of setting up hydroelectric power generation plants in the company researched.

\section{THEORETICAL FUNDAMENT}

This chapter contains a theoretical framework authors that supported the preparation of this article.

\subsection{Costs}

For the planning and execution of a project, the building company needs to have its costs well defined and delimited. Cost is the portion of the expense that is applied in the production or in any other function. Cost is the value accepted by the buyer for buying a specific good or is the sum of all aggregate values of a product since its acquisition until it reaches the marketing stage (Dutra, 2010).

The concept of costs needs to be made explicit to everyone who is part of the project. Everyone needs to 
know that any expense applied in production or in any other function within the project is characterized as cost. The wrong quantification of costs can hurt and damage the project and its management. Setting costs is a serious and critical task within the project, as it may result in injury or increase the profit for the enterprise.

Since the studies of the draft paper, the characterization of the costs must be set. This categorization allows the understanding of how costs are divided and must be applied in the Project. The four (4) main cost settings are studied. They are the direct, indirect, fixed and variable costs.

The direct costs to Dutra (2010) are the ones that can be directly appropriate to each type of good or organ at the time of its occurrence, that is, it is connected directly to each type of good or cost function. The direct costs of a project, according to Barbosa (2009) can be easily identified and quantified from necessary resources to carry out the project activities. They are directly attributed to the work of the project and therefore do not require apportionment to be allocated to projects.

According to Dutra (2010), the indirect cost is unable to segregate the portion pertaining to each product or different service at the time of application of the cost. Such separation is performed later by a special criterium called apportionment. This cost can be apportioned in different ways and the adequacy of the same depends on the branch to which the company operates and its needs, so it is an analysis of the best cost allocation.

Fixed costs are those that are always present in the production but which do not have variations. These costs that do not vary with production, such as the location of the generators in the work, will not change, regardless of the type of service or the same schedule. This cost will be the same throughout the period of the work.

On the other hand, variable costs are characterized as those that vary with the volume produced or the performed activity. The variable cost increases as the production increases and decreases when the production decreases. It is directly proportional to project activities in a given period. An example of variable cost in a power plant assembly is the working force cost.

In plant assembly projects it is impossible not to have ownership costs, which is separation by cost center. To Kamada (2013), cost center is the categorization of costs. This categorization should be consistent with the budget. The categorization is intended to show where costs are being accumulated.

For standardization and a good progress of a project there needs to be a standardization of information so that it can circulate properly within the company with greater clarity and with the reliability expected. Cost centers, for each project, form the respective chart of accounts, depending on which the project will be planned, and then the costs and the time re-quired for completion of each project element are controled.

In Figure 1, Wernke (2004) shows the necessary elements for an adequate strategic cost management.

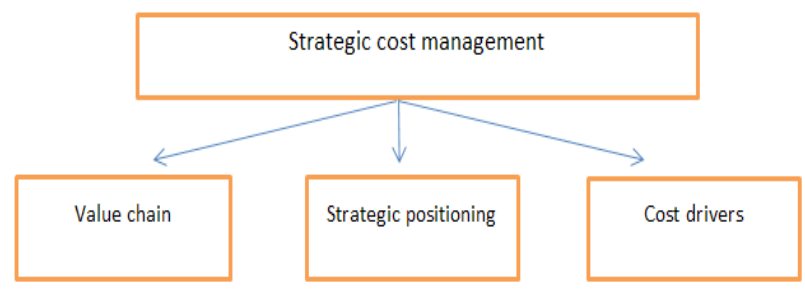

Figure 1. Strategic cost management

Source: Compiled from Wernke (2004).

\subsection{Management of costs}

Companies are in constant pursuit of management and cost control. This is a primordial factor in competitiveness and in strategic positioning in the market. According to Wernke (2004), the strategic cost management should observe, identify and analyze the cost determinants, observe the factors that actually cause the costs, called cost drivers, providing the form that reflects the most precise reality of the situation. This concept is undoubtedly very important for the strategic management of any company, clearly showing that it is necessary to know the factors that cause losses.

According to Shank et Govindarjan (2001), strategic cost management consists of these three pillars: value chain; strategic positioning and cost drivers. These factors contribute to the success of cost management in the project. The cost management should involve and give emphasis to projects that can consistently provide added and superior values to their customer, achieving these results by means of coordination and management of the cost flow. The same author also states that administrators need to monitor the performance of their companies and, therefore, must rely on relevant management information regarding to the costs and also reports that there are reliable sources of subsidies to optimize cost management. He recommends that, in order to facilitate the use and analysis of management information reports, the administrators must have available a proper sequence of information that is relevant to make decisions.

According to Dutra (2010), cost management evolves from simple systems that have been controled by the owners, for more advanced management techniques in which the control is very important. The cost is in the life of every individual and every organization that, in this aspect, 
it needs adequate management costs. The same author also points out that for the calculation of business results you need a cost management system that faithfully demonstrates the process costs of training and controls those costs. Thus, there is a clear need for organizations having their adequate controls since financial resources are increasingly expensive and scarce within the organizational context.

According to $\mathrm{PMBOK}^{\circledR}$ Guide (2008), cost management in a project involves three processes: estimating the costs, determining the budget and cost control. These three steps are closely linked, aiming to provide knowledge to analyze and to manage all the costs involved in the project.

\subsubsection{Cost assessment tools}

The basis of a good cost management is the tool used to control them; these tools are aimed at the process of monitoring the progress of the project, based on the budget and on what the project is consuming. These tools are used in accordance with a methodology that is intended to be dynamic and presents the real situation of the project once it is operated correctly.

According to Bornia (2010), the most relevant information within the modern enterprise is the measurement of waste and activities that do not add value to this information. One can check and view the amount of waste during the project and undertake efforts to improve the factors of costs where there is a higher return (profit). Based on this concept, the importance of tools for managing costs is that they must be examined, because they let you view where the waste is and this factor can make the project a failure.

Currently, there are numerous cost-control tools on the market. Softwares serve as aids for monitoring the project and its presentation. There is a wide variety of softwares, but each company must use the one that best fits with its demand and budget. A very good software is Access ${ }^{\circledR}$, it brings numerous features to control, and may add other management applications, they can show the whole situation of the project, such as 'Project'. Access ${ }^{\circledR}$ is a software that has an electronic platform to create multiple applications, you can make calculations, enter the database and even provide reports, this program is a powerful tool when it is operated and structured according to the business demands.

The use of this tool is not limited only to observe and count the costs, but also to display and to record the optimization of the resources allocated, so being able to manage if there is a better performance in the project, which areas need improvement in order to bring satisfaction and continuous improvement for the company and its customers.

The analysis for the approval of costs is easier when cost centers are well defined. As Bornia (2010, p. 21) wrote, the relevance of costs can be separated for approval in a given situation, they are the relevant and the non-relevant costs. This parameter varies depending on the situation where the project is and what was budgeted. The relevant costs are important for this approval.

\subsection{Projects of management}

The project management involves knowledge, skills, tools and techniques to carry out the project activities in order to achieve its goal and to meet the requirements (PMBOK, 2008). The project management is an essential part to achieve success in the project.

For Vargas (2009), the main features of a project are the individuality and staging of the project as well as the complexity and uncertainty. The project staging indicates the beginning and the end of the activity. It only happens when the end of the stated objectives are achieved. Each project creates a service or product that generates individuality. Several hydroelectric plants can be built with the same number of machines and the same generate capacity but each plant will be unique because each one is in different conditions, has a different complexity and the uncertainties and risks that surround each one are different. The effort of the work can be already known, the enterprise may already have well defined processes, but the individuality of the project, generates risks and uncertainties in the project practice.

According to Vargas (2009), the management aims to ensure the efficient flow occurs throughout the project time using techniques and management tools. The benefits of management are diverse as it prevents surprises and dramatic changes in the baseline design, allows new techniques of competitive advantage to be developed, provides unfavorable situations and can control them, can meet the design requirements, when using the right methodology, and optimizes all allocations of people, equipment, material resources and documents as well as facilitates the estimates for future projects.

The project is born with their particular life cycle. According to $\mathrm{PMBOK}^{\circledR}$ (2008), the life cycle of a project has four phases:

- Project start: it is the phase that involves the project beginning, the knowledge of the project scope.

- Organization and preparation: it is necessary, at this stage, to create the project management plan. At this stage, all the preparation in order to start the project happens, such as planning.

- Working and project execution: at this stage, everything that was planned is provided/delivered. 
- Project closure: this is the phase of demobilization of all resources, it happens only when the goal has been achieved and each delivery documentation and project archiving is held.

The entire project foresees risks but with well aligned planning it is possible to minimize these risks by ensuring that quality assurance can happen to processes with methodologies and well-defined planning.

\section{METHODOLOGIAL PROCEDURES}

This work was carried out in three steps:

The first step was exploratory, where the determination of the study, the study of bibliographic references and construction of the project occurred. The second stage is the fieldwork where we collected data, documents on the case and all possible and necessary information. In the third stage the analysis and interpretation of data, resulting in the submission of a report, was held.

The data collection in this research universe occurred through contact with employees, explaining the research objectives. Documents and company reports, needed for this work were obtained by direct contact with the responsible areas, when the research objectives and importance were explained.

The data were analyzed using content analysis technique, which according to Bardin (2009) is to deepen the understanding of the data collected. Thus, reports, documents or other documentation were treated as a basis for the presentation of results.

The research was based on a service company, located in Passo Fundo, RS state, Brazil. The capital of the company is private and closed, with national origin, working in the hydromechanical assembly sector for hydroelectric plants.

\section{RESULTS}

Five projects were analyzed within the company. For this work, the so-called projects $C$ and $D$ will be described.

The projects $C$ and $D$ were planned and carried out using the same river, and the two project characteristics, both physical space and facilities, nearly identical. Both projects are located by Uruguay River, near the town of Belém, in Pará state. Each plant has an installed capacity of $35 \mathrm{MW}$ and its annual output is $180,057 \mathrm{MWh}$. These two projects have helped develop the city and the region's economy, influencing the Power supply for two more cities. Once they have nearly identical characteristics they were controlled together. These projects had the scope of two turbines, two generators and a substation. It was also in the scope of providing tools, supplies, labor and all the support to its employees. The total time was 13 months each project, but that deadline was extended to 17 months. The value of each project was US\$2,000,000.00 (two million dollars). The data analysis of these two projects was carried out jointly because of their similarities.

Demonstrating the company weakness in relation to cost management, these projects were controlled in only one worksheet where the costs of the two projects were released together. In these projects, it was identified that the greatest resource allocation was the largest investment that the company needs to take to complete a project, which is the labor. About $69 \%$ of which was invested by the company was in direct labor. This high value was obtained due to the high costs that the company needs to pay and the significant value in overtime paid to employees. Other costs include as a higher percentage for the two projects, the following categories: location of third party equipment such as cranes and trucks, food for breakfast, lunch and dinner and hosting indirect work employees. These categories contributed significantly to this percentage.

The other cost that had an influence on the final result was material consumption, which is widely used throughout the project. Materials with higher costs were categorized as: outsourcing, purchase of consumption material and the material used in weld. However, it was not possible to identify some of these categories as there were not much information in the worksheet. These two projects had a negative total result of $20.9 \%$ of the total value of the project because of the lack of a proper system of cost management.

One can see that after these analyzes, the major barriers faced within that company studied is the lack of financial control because in every project the company started and finished projects with quality in its production and success in the assembly line. The project is ever finished, even when it lacks customer support. This completion occurs without being examined what brings competitive disadvantages and lack of profits for the company. Even with the lack of control, it can be seen that the profitability of all projects is negative, dramatically undermining the financial health of the company.

In Table 1, it is shown the resource allocation percentage of net revenues at work. It appears that the sum of the percentages exceeds $100 \%$ because costs were higher than the net income.

To finish these analyses, an applicative in the software program Access was studied developed throughout the duration of that work. It can help control all costs involved in the project. The same was based on all the needs that a small or large project needs, and consists of a database in which all relevant project information are inserted. 
Table 1. Percentages of Projects C and D

\begin{tabular}{lllc}
\hline PROJECT & NET REVENUE & MOST EXPENSIVE CATEGORY & $\begin{array}{l}\text { REPRESENTATION IN } \\
\text { THE TOTAL (\%) }\end{array}$ \\
\hline & & Direct labor force & 69,3 \\
& & Other Costs & 24,3 \\
C and D & US\$2.921.631,00 & Consumption Material & 17,6 \\
& & Remaining Costs & 9,7 \\
\hline
\end{tabular}

Source: The authors own

\subsection{Applicative program developed for the management of costs}

The application is composed of eight main interfaces requiring to be fed with the requested information. In five of these interfaces filling is only required when starting a new work after the start and the filling is not needed for the continuous feeding, making it easier for the user to complete the two other fields. The eighth field is for the generation of reports. This applicative can be used in various projects.

- Main menu: the main menu consists of eight buttons, the left side is composed of buttons Supplier, Customer, Cost and Cost Center and Report. These buttons are located on the left side because they use the same database for various works, once registered is in the applicative database, and when it is necessary to use it in other projects, it is already filled.

- Customer registration: all necessary information from the client to the control, as an encoding for the same, its corporate name, trade name and its company juridical number (CNPJ number, in Brazil) are in this icon. This detail of each client needs to happen because the same platform can control several projects of different customers. This registration also influences the release of data in other interfaces for better identification and organization.

- Providers: the vendor item contains: vendor code, Tax ID, Company Name, Trade Name, City and Contact.

- Center of costs: one of the basis for the success of this application, the Cost Center, contains: Cost Center Code, Level 1, Level 2, Level 3 and Description. The cost center is something in the application that should not be changed by the user because he needs to be aware of the cost centers, inserting the item correctly in the appropriate center. Along with this basis one can take the necessary information for future budgets and for the good result of the work control.
- Specification of the construction/project: in the item 'works', it is necessary to release all relevant information to the project like: work code, work number (this item is the number used in the entire company), customer, proposal number, contract number, total term, working time, time and date of commissioning and mobilization.

- Budget: this item includes the work number, cost center and the total amount budgeted for that cost center. The data for filling the budgeted item is based on the last budget by the commercial sector.

- Carried out: it must be released in the 'Carried out', the structure (cost center), plot number, value of the portion, invoice number and the supplier.

- Reports: this item demonstrates the visual project management. You can print individual reports for each cost center and a general report per project, to know the status of the project, making a comparison of what was budgeted with what was carried out.

So that the application can be used efficiently, it was created a list of technical instructions. These technical instructions contain information about each interface that the user will use and also provide information about cost centers, thus facilitating the use of the applicative. Thus, users will find it easier and have more knowledge at the time of filling of fields under their responsibilities.

Figure 2 illustrates one of the application functionality. The screen that represents the 'Report 1' shows the total budgeted amount compared to the amount realized. Here it is seen that in detemined installments, the amount realized already exceeds the budgeted amount, indicating a possible injury. 


\begin{tabular}{|c|c|c|c|}
\hline elatór & & & \\
\hline Estrutura & Parcela & Valor Total & Realizado \\
\hline & $\underline{13}$ & $\mathrm{R} \$ 512.500,00$ & $\mathrm{R} \$ \mathbf{6 1 8 . 5 7 8 , 9 8}$ \\
\hline & $\underline{14}$ & $\mathrm{R} \$ 100.000,00$ & $\mathrm{R} \$ 111.000,00$ \\
\hline & $\underline{15}$ & $\mathrm{R} \$ 37.500,00$ & $\mathrm{R} \$ 36.302,79$ \\
\hline & $\underline{17}$ & $\mathrm{R} \$ 12.000,00$ & $\mathrm{R} \$ 12.050,00$ \\
\hline & $\underline{24}$ & $\mathrm{R} \$ 75.000,00$ & \\
\hline
\end{tabular}

Total geral

Figure 2. Report visual management Source: The auothors own

\section{CONCLUSION}

At the end of this work, it is important that the evidence raised in the survey is in line with the overall objective of the study. The aim of this study was to design a cost control methodology that would assist in cost management and in the management of the company projects. Together with the creation of application demonstrated in this work, the main objective is achieved, as evidenced during the development of this work that the company needed this tool to improve its project management with an appropriate cost control.

The provision of information to sectors through reports using the visual management model will surely bring a contribution to the company because the trend is that employees become more involved with the processes, viewing points that may occur contributing cost rationalization in this way with a most appropriate magement of the costs in the projects.

In the step preceding the implementation, it is recommended the involvement of all the technical parts of the company to understand and to use the application, so that in this way, everyone can have access to the information generated by the applicative. It is also recommended for everyone to have access to information, make tables in the sectors involved with the fortnightly reports that the applicative generates. Increasing the purpose of the applicative is to improve the cost management and to develop visual management inside the company.

Is also important to note that the analysis of the results of this study shows that a methodological structuring of cost control is vital for administrators to have reports at hand in an appropriate sequence of information that is relevant for their decision makings.

Finally, even considering the limitations of this paper, it is evident the importance of an appropriate cost control system, helping to improve the management process and also the company finance.

\section{REFERENCES}

Barbosa, C. (2009) Gerenciamento de custos em projetos. 3. ed. Rio de Janeiro: Editora FGV.

Bardin, L. (2009) Análise de conteúdo. Lisboa, Portugal; Edições 70 LDA.

Bornia, A.C. (2010) Análise gerencial de custos: aplicação em empresas modernas. 3. ed. São Paulo: Atlas.

Dutra, R.G. (2010) Custos: uma abordagem prática. 7. ed. São Paulo: Atlas.

GUIA PMBOK ${ }^{\circledR}$. (2008) Um guia do conhecimento em gerenciamento de projetos. 4 . ed.

Kamada, S. (2013) Indicadores para a estabilidade produtiva. Disponível em: <htttp://www.lean.org.br/ artigos>. Accessed 16 november 2013.

Shank, J. K.; Govindarajan, V. A revolução dos custos. Rio de Janeiro: Campus, 2001.

Vargas, R. (2009) Manual prático do plano de projeto: utilizando o $\mathrm{PMBOK}^{\circledR}$ Guide 4th ed. 4. ed. Rio de Janeiro: Brasport.

Wernke, R. (2004) Gestão de custos: uma abordagem prática. 2. ed. São Paulo: Atlas. 